\title{
ATENDIMENTO AOS REQUISITOS DE DESEMPENHO DA NBR 15575 - SISTEMAS DE VEDAÇÕES VERTICAIS
}

\section{COMPLIANCE WITH NBR 15575 PERFORMANCE REQUIREMENTS - VERTICAL SEALING SYSTEMS}

\author{
Aline Nunes Lopes ${ }^{1}$, Jaciara Braz Pires ${ }^{2}$, Sayonara Maria de Moraes Pinheiro ${ }^{3}$, Milton Paulino da \\ Costa Junior ${ }^{*}$ \\ ${ }^{1}$ Engenheira civil, graduada na UFES/Vitória/ES, Brasil, alinenunnes@ymail.com \\ 2 Engenheira civil, graduada na UFES/Vitória/ES, Brasil, piresjaciara8@gmail.com \\ ${ }_{3}^{3}$ Pós-doutorado em engenharia civil pelo Instituto de Ciencia y Tecnologia del Hormigón de la Universitat Politécnica de Valencia, \\ professora da UFES, Vitória/ES, Brasil, sayonara.pinheiro@gmail.com I \\ ${ }^{4}$ Doutor em engenharia civil pela Unicamp, professor da UFES, Vitória/ES, Brasil, milton.paulino@gmail.com \\ ${ }^{*}$ Autor de correspondência
}

\section{Resumo}

O atendimento aos requisitos da Norma de Desempenho de edificações habitacionais (NBR 15575) é importante, pois nela estão traduzidas as necessidades da sociedade brasileira no que se refere às exigências dos usuários dos sistemas que compõem os edifícios habitacionais. Este trabalho tem o objetivo de analisar a implementação da Parte 4 Sistemas de vedações verticais internas e externas da Norma de Desempenho ABNT - NBR 15575:2013, em uma empresa construtora que possui sistema de gestão da qualidade baseado no Programa Brasileiro de Qualidade e Produtividade do Habitat (PBQP-H). Para isso, foi realizado um estudo de caso, dividido nas etapas: amostragem, coleta de dados e análise de resultados. Os dados foram coletados por meio de entrevistas, análises documentais e observação de registros fotográficos do processo construtivo de vedação vertical externa. $O$ estudo mostrou que a empresa avaliada conseguiu atender a quase todos os requisitos da norma (Parte 4 da NBR 15575) utilizando Fichas de Avaliação de Desempenho (FAD), exigindo relatórios de ensaios dos seus fornecedores e especificações de materiais e referentes, bem como os requisitos de segurança contra incêndio. Porém, verificou-se que na prática a execução do sistema de vedação diverge em alguns aspectos do que é estabelecido na documentação apresentada e analisada, o que pode comprometer o atendimento aos requisitos da norma e o bom desempenho da obra.

Palavras-chave: Desempenho. Vedação Externa. Alvenaria. Edificações Habitacionais. Qualidade.

\begin{abstract}
Meeting the requirements of the housing building performance standard (NBR 15575) is important, as it reflects the needs of Brazilian society with regard to the requirements of the users of the systems that make up the housing buildings. This work aims to analyze the implementation of Part 4 - Internal and external vertical sealing systems of the Performance Standard ABNT NBR 15575: 2013, in a construction company that has a quality management system based on the Brazilian Habitat Quality and Productivity Program (PBQP-H). For this, a case study was carried out, divided into the stages: sampling, data collection and analysis of results. The data were collected through interviews, documentary analysis and observation of photographic records of the construction process of vertical sealing. The study showed that the evaluated company was able to meet almost all the requirements of the standard (Part 4 of NBR 15575) using Performance Assessment Sheets (FAD), requiring test reports from its suppliers and specifications of materials and references, as well as fire safety requirements. However, it was found that in practice the execution of the sealing system differs in some aspects from what is established in the documentation presented and analyzed, which can compromise the compliance with the requirements of the standard and the good performance of the construction work.
\end{abstract}

Keywords: Performance. External Fencing. Masonry. Residential Buildings. Quality.

(CUNIS-MG. All rights reserved. 


\section{INTRODUÇÃO}

Em fevereiro de 2013, a Associação Brasileira de Normas Técnicas (ABNT) tornou pública a última versão da norma NBR 15575 (ABNT, 2013), denominada "Edificações habitacionais Desempenho", a qual é conhecida no setor da construção civil como "Norma de Desempenho".

O principal objetivo da NBR 15575 (ABNT, 2013) é estabelecer requisitos mínimos de conforto, acessibilidade, higiene, estabilidade, vida útil, segurança estrutural e pela prevenção de incêndios de edificações.

O atendimento à NBR 15575 tem importância relevante, pois nesta norma são apresentadas as exigências dos usuários no que se refere aos requisitos que os sistemas de edificações devem possuir. A incorporação dessa norma ao Programa Brasileiro de Qualidade e Produtividade do Habitat (PBQP-H) reitera a obrigatoriedade de seu cumprimento e de sua relevância (ZANINI, 2011).

O PBQP-H é um programa que foi criado pelo governo federal em 1998 e que possui como meta a melhoria da qualidade e produtividade das organizações brasileiras ligadas ao setor da construção civil. Paralelamente à sua criação, foi dado início ao projeto de desenvolvimento da norma brasileira de desempenho (NBR 15575), que teve sua primeira publicação em junho de 2008 (MCID, 2019).

Nesse contexto, verificou-se que estudar a forma como as empresas estão se modificando para atender à norma NBR 15575 é importante, pois tais estudos permitem aprofundar o conhecimento no tema e facilitar a compreensão e adaptação de todos os intervenientes envolvidos no processo: fornecedores de insumos, construtoras, incorporadoras, projetistas e clientes (LIMA, 2018; CORBIOLI, 2016).

O presente trabalho se justifica no entendimento de que a NBR 15575 (ABNT, 2013) não é somente uma ferramenta de qualidade da construção civil, mas também um importante instrumento de garantia da qualidade dos imóveis que são entregues à sociedade. Dessa forma, este trabalho teve o objetivo de analisar quais métodos foram utilizados por uma empresa construtora, alvo do estudo de caso, para atendimentos aos requisitos da norma NBR 15575 (ABNT, 2013), parte 4 (Sistemas Verticais de Vedações Internas e Externas - SVVIE) e verificar se esses requisitos estão sendo atendidos na obra.

\section{FUNDAMENTAÇÃO TEÓRICA}

De acordo com Ministério das Cidades (MCID, 2019), há mais de três mim (3.000) empresas com certificação do PBQP-H em vigência no Brasil. Nesse cenário, a incorporação da Norma de Desempenho ao PBQP-H implica que as construtoras que desejam permanecer no programa coloquem em prática estratégias e soluções visando sua adequação à nova realidade, ou seja, busquem soluções para atenderem os requisitos da norma NBR 15575 (ABNT, 2013).

A NBR 15575 - Edificações habitacionais - Desempenho (ABNT, 2013), estabeleceu regras importantes para a concepção de produtos imobiliários e, de acordo com profissionais da área, a maior dificuldade em cumpri-las está na inserção de um novo modelo para os projetistas (SACHS e NAKAMURA, 2013). Segundo Borges (2019), embora o conceito seja de simples entendimento, a aplicação prática da NBR 15575 (ABNT, 2013) não é tão simples quanto aparenta pois, diversos fatores influenciam a obtenção do desempenho requerido e alguns deles são de responsabilidade 
dos incorporadores, projetistas e construtores e dos próprios usuários dos imóveis (todos os intervenientes).

A NBR 15575 (ABNT, 2013) é embasada, principalmente, nas exigências dos usuários para edifícios habitacionais em relação à segurança, habitabilidade e sustentabilidade. As exigências de segurança envolvem os requisitos de integridade física da edificação e do usuário, sendo expressas pelos fatores: segurança estrutural; segurança contra o fogo; segurança no uso e operação e manutenibilidade. As exigências de habitabilidade representam os aspectos relativos ao bem-estar dos usuários e são expressas pelos fatores: estanqueidade; desempenho térmico; desempenho acústico; desempenho lumínico; saúde, higiene e qualidade do ar; funcionalidade e acessibilidade; conforto tátil e antropodinâmico. Já as exigências de sustentabilidade são relativas à manutenção do ambiente construído e os seus entornos, sendo expressas pelos fatores: durabilidade; manutenibilidade e impacto ambiental.

Para uma melhor representação, a norma NBR 15575 foi dividida em seis (6) partes:

- Parte 1: Requisitos gerais;

- Parte 2: Requisitos para os sistemas estruturais;

- Parte 3: Requisitos para os sistemas de pisos;

- Parte 4: Requisitos para os sistemas de vedações internas e externas (SVVIE);

- Parte 5: Requisitos para os sistemas de coberturas (SC);

- Parte 6: Requisitos para os sistemas hidrossanitários.

A parte 4 abrange os requisitos segurança estrutural, segurança contra incêndio, estanqueidade, desempenho térmico, desempenho acústico, desempenho lumínico, durabilidade e manutenibilidade de Sistemas de Vedações Verticais Internas e Externas (SVVIE).

Para esses requisitos de desempenho, pode-se destacar algumas considerações:

- Desempenho estrutural dos SVVIE - um dos itens mais relevantes dessa exigência é o de impactos incidentes em guarda-corpos e parapeitos, sistemas que devem possuir, no mínimo, laudos de protótipos, pois geram grande risco aos usuários durante sua utilização, os quais, contudo, eram negligenciados antes da exigência da Norma de Desempenho (CORDOVIL, 2013; COSTELLA et al., 2017).

- Segurança contra incêndio - a maior parte das construtoras atende aos critérios indicados para o SVVIE; porém nem todas possuem laudos que comprovem estas informações, como também não possuem projetos contendo detalhamento e suas indicações específicas (JANUZZI; VERCESI, 2019; SHIN, 2016).

- Estanqueidade dos SVVIE - Costella et al. (2017) verificaram que as obras geralmente também não apresentam laudos de ensaio, detalhamentos das impermeabilizações; não havendo especificações relativas à interface entre os sistemas de pisos e vedações que garantam a estanqueidade dos ambientes em áreas molhadas.

- Desempenho térmico, tem-se a necessidade de realização e apresentação de cálculo de transmitância e capacidade térmica dos SVVIE, os quais são de fácil realização, mas que não eram executados pelos projetistas anteriormente à entrada em vigor da NBR 15575 (ABNT, 2013). Costella et al. (2017) observaram conformidade apenas dos critérios 
submetidos à análise por órgãos competentes com a finalidade de obter aprovação técnica.

Apesar da entrada em vigor da NBR 15575 (ABNT, 2013) ter sido um marco para a garantia da qualidade de edificações e atendimento às exigências dos usuários, bem como ter proporcionado diversos impactos positivos, tais como aumento da busca por qualificação, diminuição do número de escritórios de projetos, melhor qualificação e qualidade dos escritórios remanescentes e, busca de seguros para garantir proteção aos riscos, o mercado da construção civil sofreu alguns impactos negtivos, principalmente, no que diz respeito à gestão de riscos após a vigência da NBR 15575 (ABNT, 2013), pois verificou-se um aumento .de demandas judiciais por parte dos consumidores finais contra as construtoras (SINAENCO, 2015).

Segundo o SINAENCO (2015), uma das maiores dificuldades encontradas no entendimento dos requisitos prescritos pela NBR 15575 (ABNT, 2013) tem sido a comprovação do desempenho de alguns sistemas que exigem vários ensaios de custos elevados. Além desse custo, a necessidade de adquirir componentes com certificação de qualidade também contribuem para um aumento expressivo de custo, que muitas vezes pode inviabilizar a implantação de empreendimentos habitacionais, principalmente os de caráter social.

Entretanto, apesar das dificuldades enfrentadas, a NBR 15575 (ABNT, 2013) pode elevar o patamar da qualidade do setor da construção civil brasileiro, norteando o mercado para a melhoria da qualidade, incorporando o conceito de valor real dos produtos e serviços, levando em conta o valor agregado e dos custos indiretos provenientes de manutenções (KERN; SILVA; KAZMIERCZAK, 2014).

\section{MÉTODOS DE TRABALHO}

Os procedimentos adotados para execução do presente trabalho são apresentados esquematicamente na Figura 1.

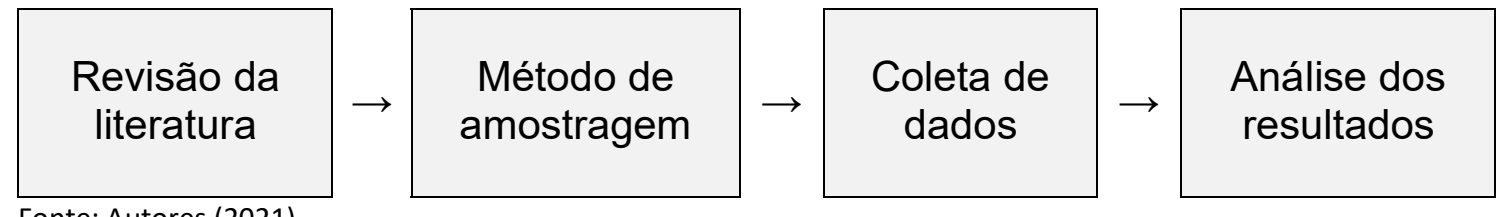

Figura 1 - Fluxograma das Etapas do Trabalho.

Revisão da literatura: Realizada uma revisão bibliográfica para dar embasamento teórico ao trabalho.

Amostragem: A amostra selecionada para essa pesquisa foi uma empresa que, obrigatoriamente, já possuísse a certificação no PBQP-H e que estivesse próxima da data de renová-la, ou seja, estivesse se adequando com a atualização de junho/2018 do regimento SiAC (PBQP-H), onde consta a obrigatoriedade de atender à NBR 15575 (ABNT, 2013).

A seleção da empresa foi feita com base nos seguintes critérios: possuir pelo menos uma obra em andamento e acesso facilitado para visitas dos autores deste estudo; facilidade no contato com engenheiros e outros responsáveis pela obra e disponibilidade no fornecimento de informações e documentos. 
Coleta de dados: A coleta de dados foi realizada por meio de fontes documentais, entrevistas e observações realizadas em campo e realização de registros fotográficos.

O Quadro 1 sintetiza a pesquisa documental deste trabalho, sendo apresentados os requisitos analisados e os documentos que comprovassem o atendimento aos requisitos. A coleta de dados também foi realizada por meio de entrevistas.

Quadro 1 - Requisitos e Documentos Para Análise Documental.

\begin{tabular}{|c|c|}
\hline REQUISITOS A ANALISAR & DOCUMENTO COMPROBATÓRIO \\
\hline $\begin{array}{l}\text { Deslocamentos, fissuras e ocorrência de falhas } \\
\text { nos sistemas de vedações verticais externas } \\
\text { (SVVIE) }\end{array}$ & $\begin{array}{c}\text { Relatório de ensaio realizado conforme ABNT NBR 10821-3 } \\
\text { (ABNT, 2017) ou Anexo G da ABNT NBR 15575-4 (ABNT, 2013) } \\
\text { para SVV sem função estrutural. }\end{array}$ \\
\hline $\begin{array}{c}\text { Solicitação de cargas provenientes de peças } \\
\text { suspensas atuantes nos sistemas de vedações } \\
\text { externas }\end{array}$ & $\begin{array}{l}\text { Relatório de ensaio, em laboratório ou protótipo, de acordo } \\
\text { com o método de ensaio indicado no Anexo A da ABNT NBR } \\
\qquad 15575-4 \text { (ABNT, 2013). }\end{array}$ \\
\hline $\begin{array}{l}\text { Impacto de corpo mole nos sistemas de vedações } \\
\text { verticais externas, com ou sem função estrutural }\end{array}$ & $\begin{array}{l}\text { Relatório de ensaio tipo em laboratório ou em campo, de } \\
\text { acordo com a ABNT NBR } 11675 \text { (ABNT, 2016). }\end{array}$ \\
\hline Ações transmitidas por portas & $\begin{array}{l}\text { Relatório sistêmico de fechamento brusco da porta realizado } \\
\text { segundo a ABNT NBR 15930-2 (ABNT, 2018). }\end{array}$ \\
\hline $\begin{array}{l}\text { Impacto de corpo duro incidente nos SVVIE, com } \\
\text { ou sem função estrutural }\end{array}$ & $\begin{array}{l}\text { Relatório de ensaio tipo, em laboratório ou em campo, de } \\
\text { acordo com o Anexo B ou ABNT NBR 11675(ABNT, 2016). }\end{array}$ \\
\hline $\begin{array}{l}\text { Cargas de ocupação incidentes em guarda-corpos } \\
\text { e parapeitos de janelas }\end{array}$ & $\begin{array}{l}\text { Relatório de ensaio tipo, em laboratório ou em campo, de } \\
\text { acordo com os métodos de ensaio indicados na ABNT NBR } \\
\qquad 14718 \text { (ABNT, 2019). }\end{array}$ \\
\hline Segurança contra incêndio & $\begin{array}{l}\text { Relatório de ensaios realizados conforme a ABNT NBR } 5628 \\
\qquad(A B N T, 2001) .\end{array}$ \\
\hline Estanqueidade & $\begin{array}{l}\text { Relatório de inspeção em campo, relatório de ensaio de } \\
\text { estanqueidade e projeto. }\end{array}$ \\
\hline $\begin{array}{l}\text { Desempenho térmico adequação de paredes } \\
\text { externas }\end{array}$ & $\begin{array}{l}\text { Relatório que garanta cálculos conforme ABNT NBR 15220-2 } \\
\text { (ABNT, 2005). }\end{array}$ \\
\hline Aberturas para ventilação & Projeto arquitetônico \\
\hline Desempenho acústico & Relatório de ensaio de acordo com a ISO 10140-5 (ISO, 2010). \\
\hline $\begin{array}{l}\text { Durabilidade e manutenibilidade de paredes } \\
\text { externas - SVVE }\end{array}$ & $\begin{array}{l}\text { Relatório de ensaio conforme anexo E da ABNT NBR 15575-4 } \\
\qquad \text { (ABNT, 2013). }\end{array}$ \\
\hline $\begin{array}{c}\text { Vida útil do projeto dos sistemas de vedações } \\
\text { verticais externas }\end{array}$ & Manual de operação. \\
\hline $\begin{array}{l}\text { Manutenibilidade dos sistemas de vedações } \\
\text { verticais externas }\end{array}$ & $\begin{array}{l}\text { Manual de operação, uso e manutenção dos sistemas de } \\
\text { vedação vertical. }\end{array}$ \\
\hline
\end{tabular}

Fonte: Autores (2021).

As entrevistas foram realizadas com o engenheiro da empresa e seguiram roteiros elaborados com perguntas previamente definidas. Inicialmente foi realizada uma entrevista (Entrevista 1) buscando coletar as seguintes informações: 
- Caracterização da empresa. Perguntando-se sobre a sua data de fundação, número de funcionários, área de atuação e de abrangência, número de obras em andamento. Vale ressaltar que o estudo foi realizado em uma empresa situada na cidade de Colatina-ES;

- Sistema de Gestão da Qualidade da empresa, baseado no PBQP-H. Perguntando-se desde quando a empresa implantou o PBQP-H, nível de certificação que possui e se tem algum outro programa de qualidade;

- Como a empresa garante que as exigências do usuário sejam atendidas (segurança, habitabilidade, sustentabilidade etc.). Perguntando sobre a forma como a empresa garante que as exigências do usuário relativas à segurança, habitabilidade e sustentabilidade eram atendidas;

- Incumbências dos intervenientes (caracterização do desempenho pelo fornecedor, projetista e incorporador). Perguntando-se: como os fornecedores caracterizam o desempenho de acordo com a Norma de Desempenho, como é realizada esta caracterização; como o projetista estabelece a Vida Útil de Projeto (VUP) de cada sistema que compõe a norma; qual o papel do projetista no que se refere aos materiais, produtos e processos envolvidos; se é elaborado por parte do construtor ou incorporador o manual de operação e uso e manutenção (deve ser entregue ao proprietário da unidade) e quais as informações principais e indispensáveis contidas no mesmo.

Na segunda entrevista (Entrevista 2) foram realizadas perguntas sobre o atendimento aos requisitos de desempenho especificados na NBR 15575 - parte 4 (ABNT, 2013). Nesta entrevista foram realizadas perguntas referentes aos métodos utilizados de ensaios laboratoriais, ensaios de tipo ${ }^{1}$, ensaios de campo, inspeções em protótipos ou em campo, simulações, análise de projetos e como os resultados eram registrados.

Para cada requisito pesquisado, os entrevistados respondiam como eram realizados os ensaios de avaliação de desempenho, qual método utilizado e como eram registrados os resultados desta investigação. Os requisitos estudados foram:

- Desempenho estrutural;

- Segurança contra incêndio;

- Segurança, uso e operação;

- Estanqueidade;

- Desempenho térmico;

- Desempenho acústico;

- Desempenho lumínico;

- Durabilidade e manutenibilidade.

A avaliação de campo e realização de registros fotográficos foram realizados com o objetivo de verificar a execução dos serviços de alvenaria em obra. Teve-se como objetivo analisar

\footnotetext{
${ }^{1}$ Ensaios de tipo - são ensaios realizados em um protótipo ou em uma pequena amostra retirada da produção inicial de um material, componente ou sistema construtivo, para verificar seu potencial de atendimento a uma especificação técnica. Esses ensaios são realizados para determinar as características de um produto, que depois deverão ser repetidas na produção em série (CBIC, 2013; CBIC, 2015).
} 
e fotografar as soluções adotadas para o atendimento da parte 4 da norma NBR 15575 (ABNT, 2013), e como estas são cumpridas em campo. Assim, foram realizadas visitas técnicas a obra para acompanhar todas as etapas construtivas da alvenaria de blocos cerâmicos, desde a chegada dos materiais a obra até a finalização do serviço.

Análise dos resultados: Após a coleta dos dados, a eficiência das soluções adotadas pela empresa para atender aos requisitos dos sistemas de vedação interno e externo foram comparadas com os métodos de avaliação e critérios de desempenho que constam na parte 4 da NBR 15575 (ABNT, 2013). Com base nas informações obtidas em campo pode-se verificar se a empresa, atende ou não os requisitos da norma e quais recursos ela utiliza para o atendimento.

\section{RESULTADOS E DISCUSSÕES}

$\mathrm{Na}$ obra estudada utilizou-se alvenaria convencional com tijolos cerâmicos de 9 furos com dimensões de $140 \times 190 \times 290 \mathrm{~mm}$ como sistema construtivo de vedação externa. O sistema selecionado pela empresa para avaliar o desempenho dos mesmos é detalhado em seu plano de controle tecnológico (PCT). Esse plano define qual método deve ser utilizado para comprovar o desempenho do sistema construtivo utilizado e/ou a qualidade do material.

Para cada material ou serviço utilizado, a empresa criou um plano de controle tecnológico, indicando qual a atividade, a norma utilizada para essa checagem, quando deve ser realizada, seu responsável, quais as evidências utilizadas para garantir o atendimento a esse plano e os critérios para compra e inspeção do material. De acordo com Inntelectus (2018), com o plano de controle tecnológico objetiva-se direcionar a empresa quanto ao controle de materiais e serviços, para assegurar o desempenho da edificação.

Para atender aos requisitos da parte 4 da NBR 15575 (ABNT, 2013) quanto à vedação externa, a empresa faz uso de uma Ficha de Avaliação de Desempenho - FAD. Nesse documento são apresentados os resultados da avaliação técnica e as condições de execução, uso e manutenção de um sistema convencional. De acordo com CBIC (2014), essa ficha serve para comprovar que determinado sistema construtivo tem seus desempenhos testados e segue as especificações da Norma de Desempenho.

Vale ressaltar que as FADs são documentos técnicos, desenvolvidos por empresas em conjunto com Instituições Técnicas Avaliadoras no âmbito do Sistema Nacional de Avaliações Técnicas de produtos inovadores e sistemas convencionais (SiNAT), do PBQP-H, que contém parâmetros de desempenho de um sistema construtivo, considerando as características técnicas de seus materiais e componentes constituintes e as condições de execução (CLETO et al., 2021).

Com o uso das FADs, a construtora pode ser eximida da necessidade de comprovações adicionais de atendimento à NBR 15575 (ABNT, 2013), desde que as obras sejam executadas conforme previsto nessas fichas. Em suma, constata-se que a FAD serve para atestar que um sistema construtivo tem seus desempenhos testados e está seguindo as especificações da Norma de Desempenho de edificações.

A FAD usada como referência de sistema construtivo para o projeto é a "Sistema de Vedação Vertical Externa 001" (SVVE 001), que trata de paredes externas constituídas por alvenaria em blocos cerâmicos vazados, assentados com furos na vertical de revestimento interno em gesso e externo de argamassa. O MCID (2019) apresenta um esquema de como a alvenaria deve ser executada, em conformidade com conforme a FAD (Figura 2). 

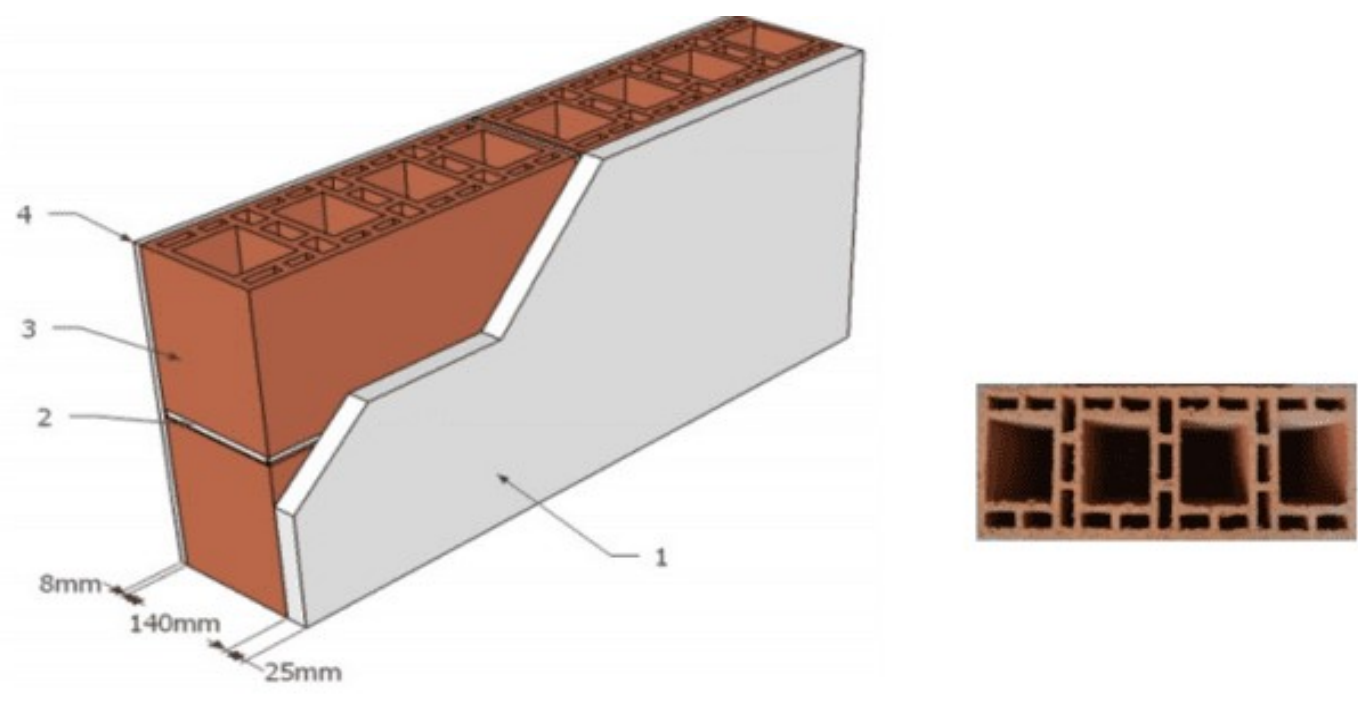

Fonte: FAD SVVIE 001 (Ministério das Cidades, 2019).

Figura 2 - Esquema de Execução da Vedação Externa Conforme FAD.

A FAD também especifica quais as características geométricas, desempenho estrutural, retenção de água, densidade e massa seca de todos os componentes do sistema construtivo. De acordo com CBIC (2014), a FAD é um importante instrumento para que a construtora possa demonstrar a realização de ensaios, pareceres e simulações comprovando que o sistema atende aos requisitos da Norma de Desempenho.

\subsection{Segurança Estrutural}

No Quadro 2 pode-se observar os documentos apresentados pela empresa para comprovar a eficácia do sistema de vedação no requisito segurança estrutural. Nesse Quadro são apresentadas as evidências obtidas para atendimentos ao requisito de desempenho estudado (segurança estrutural), adquiridas por meio da FAD. Os documentos comprobatórios constam basicamente de resultados de ensaios e laudos.

Observado o Quadro 2, verifica-se que todos os requisitos aplicáveis de desempenho estrutural avaliados têm sua eficácia comprovada pela FAD, exceto o requisito estabilidade e resistência estrutural (SVVIE) que não é aplicável pois a vedação estudada não tem função estrutural. Contudo, o uso da FAD é apenas parte do processo de controle tecnológico, cabendo à construtora executar e comprovar o serviço realizado de acordo com as premissas da mesma.

Em visita realizada a obra verificou-se que a empresa não segue, em sua totalidade, as premissas de projetos da ficha de avaliação de desempenho FAD SVVE 001, pois não atende as premissas definidas na FAD quanto ao tipo de bloco cerâmico e assentamento da alvenaria.

A Figura 3 apresenta o elemento cerâmico utilizado na obra para a vedação externa, tratando-se de tijolos cerâmicos de nove (9) furos com dimensões de 140x190x290mm, diferente do bloco cerâmico de 4 furos com dimensões de 140x190x390mm apresentado na FAD (SVVE 001) (Figura 2); divergindo dados apresentados na FAD com os utilizados na obra. 
LOPES, Aline Nunes Lopes; PIRES, Braz Pires; PINHEIRO, Sayonara Maria de Moraes; COSTA JUNIOR, Milton Paulino Atendimento aos requisitos e desempenho da NBR 15575 - Sistemas de vedações verticais

Quadro 2 - Análise Documental - Segurança Estrutural dos SVVE.

\begin{tabular}{|c|c|c|c|c|c|}
\hline REQUISITOS A ANALISAR & DOCUMENTO COMPROBATÓRIO & FAD & FORNECEDOR & $\begin{array}{l}\text { NÃO SE } \\
\text { APLICA }\end{array}$ & $\begin{array}{c}\text { NÃO } \\
\text { POSSUI }\end{array}$ \\
\hline $\begin{array}{l}\text { Estabilidade e resistência } \\
\text { estrutural dos sistemas de } \\
\text { vedação interno e } \\
\text { externos (SVVIE) }\end{array}$ & $\begin{array}{l}\text { Laudo sísmico e declaração em } \\
\text { projeto }\end{array}$ & & & $x$ & \\
\hline $\begin{array}{l}\text { Deslocamentos, fissuras e } \\
\text { ocorrência de falhas nos } \\
\text { SVVIE }\end{array}$ & $\begin{array}{l}\text { Relatório de ensaio realizado } \\
\text { conforme NBR 10.821-3 Anexo G } \\
\text { da Parte } 4 \text { da ABNT NBR } 15575 \\
\text { para SVV sem função estrutural }\end{array}$ & $x$ & & & \\
\hline $\begin{array}{l}\text { Solicitação de cargas } \\
\text { provenientes de peças } \\
\text { suspensas atuantes nos } \\
\text { SVVIE. }\end{array}$ & $\begin{array}{l}\text { Relatório de ensaio, em } \\
\text { laboratório ou protótipo, de } \\
\text { acordo com o método de ensaio } \\
\text { indicado no Anexo A da Parte } 4 \text { da } \\
\text { ABNT NBR } 15575\end{array}$ & $x$ & & & \\
\hline $\begin{array}{l}\text { Impacto de corpo mole } \\
\text { nos SVVIE com ou sem } \\
\text { função estrutural }\end{array}$ & $\begin{array}{l}\text { Relatório de ensaio em laboratório } \\
\text { ou em campo, de acordo com a } \\
\text { ABNT NBR } 11675\end{array}$ & $x$ & & & \\
\hline $\begin{array}{l}\text { Ações transmitidas por } \\
\text { portas }\end{array}$ & $\begin{array}{c}\text { Relatório sistêmico de fechamento } \\
\text { brusco da porta realizado segundo } \\
\text { a ABNT NBR 15930-2. }\end{array}$ & $x$ & & & \\
\hline $\begin{array}{l}\text { Impacto de corpo duro } \\
\text { incidente nos SVVIE com } \\
\text { ou sem função estrutural }\end{array}$ & $\begin{array}{c}\text { Relatório de ensaio, em } \\
\text { laboratório ou em campo, de } \\
\text { acordo com o Anexo B ou ABNT } \\
\text { NBR } 11675\end{array}$ & $x$ & & & \\
\hline $\begin{array}{l}\text { Cargas de ocupação } \\
\text { incidentes em guarda- } \\
\text { corpos e parapeitos de } \\
\text { janelas }\end{array}$ & $\begin{array}{l}\text { Relatório de ensaio, em } \\
\text { laboratório ou em campo, de } \\
\text { acordo com os métodos de ensaio } \\
\text { indicados na ABNT NBR } 14718\end{array}$ & $x$ & & & \\
\hline
\end{tabular}

Fonte: Autores (2021).

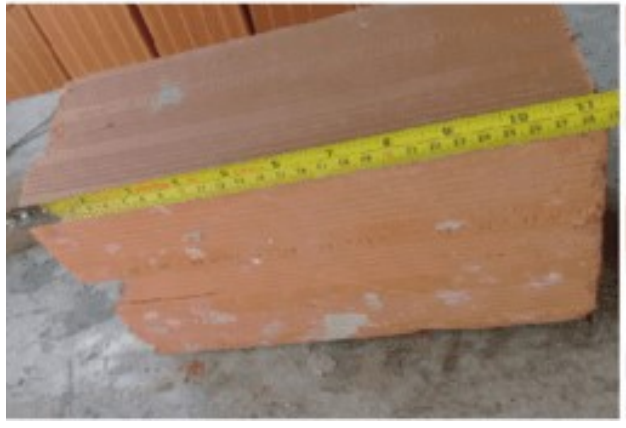

Fonte: Autores (2021).
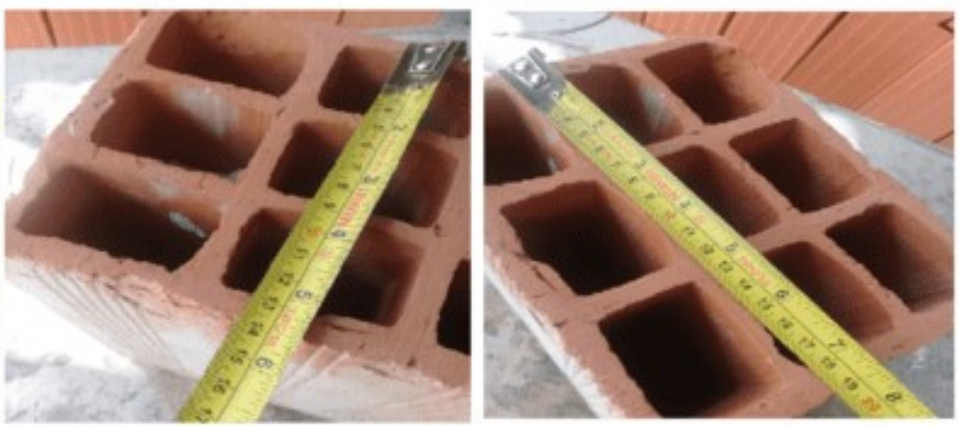

Figura 3 - Dimensões do Bloco Utilizado na Obra, em Desacordo com a FAD. 
Também foi possível observar, como mostrado na Figura 4a, da fachada lateral da edificação, que o assentamento dos elementos cerâmicos (tijolos) foi feito com furos na horizontal, diferente do estabelecido na FAD (furos na vertical). Além disso, o revestimento interno da edificação está sendo executado com argamassa no lugar de gesso como estabelece a FAD (Figura 4b).

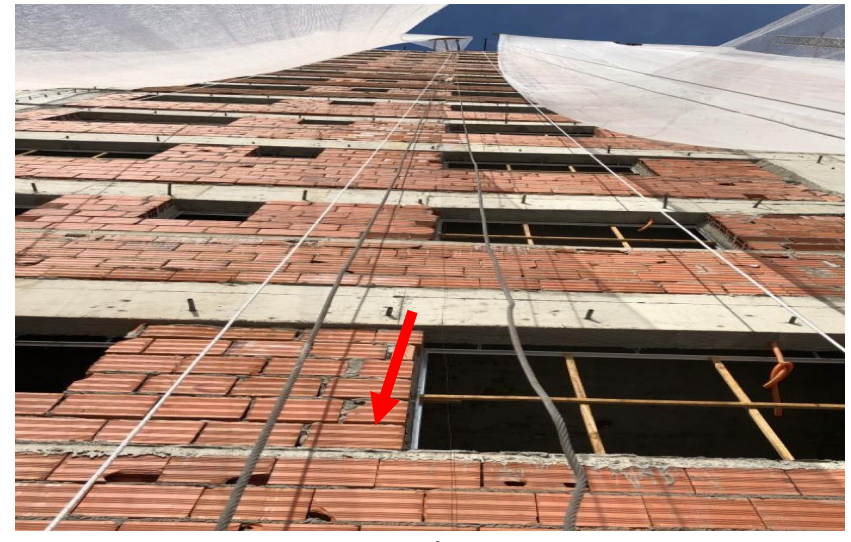

a)

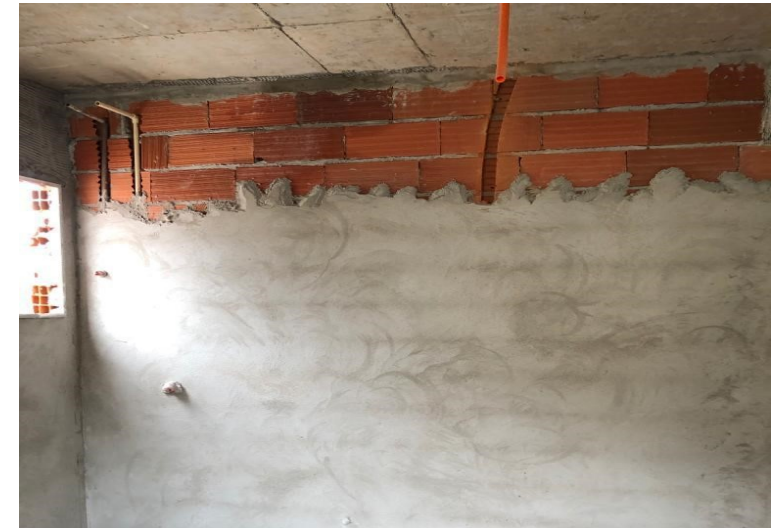

b)

Fonte: Autores (2021).

Figura 4 - Etapas d e Execução: a) Fachada Lateral da Obra com Blocos Cerâmicos Assentados na Horizontal; b) Revestimento Interno da Edificação em Argamassa

De acordo com Peres, Benachour e Santos (2008), o revestimento de gesso melhora sensivelmente $\mathrm{o}$ isolamento térmico em paredes por causa de seu baixo coeficiente de condutividade térmica; contribui para o isolamento térmico de ruídos transmitidos pelo ar e advindos de impactos, além de ser capaz de combater a propagação do fogo, estabilizando a temperatura da região onde o gesso foi utilizado, por um determinado período. Ferreira (2017) afirma que o revestimento de gesso possui um bom isolamento acústico e térmico.

O revestimento em gesso não apresenta retração hidráulica, o que torna seu desempenho em uso superior ao da argamassa de cimento. A possibilidade de surgimento de fissuras é muito pequena, a não ser que a espessura do revestimento seja maior que $5 \mathrm{~mm}$ (QUINALIA, 2005). É importante também considerar que o uso de argamassa aumenta a carga na estrutura por ter maior densidade que revestimentos em gesso (FERREIRA, 2017).

\subsection{Segurança contra incêndio}

Como mostrado no Quadro 3, a comprovação da avaliação do sistema quanto à segurança de incêndio também fica a cargo da FAD.

É importante salientar que a FAD apresentada no Quadro 3 não apresenta relatórios de ensaios que comprovem o atendimento aos requisitos de segurança contra incêndio previstos na norma; isso ocorre porque a FAD indica que os materiais usados nesse sistema construtivos são incombustíveis (classe I), portanto, de acordo com a Norma de Desempenho, são dispensados de ensaios para comprovar atendimento a este requisito. 
Quadro 3 - Análise Documental Quanto à Segurança Contra Incêndio nos SVVE.

\begin{tabular}{|c|c|c|c|c|c|}
\hline REQUISITOS A ANALISAR & DOCUMENTO COMPROBATÓRIO & FAD & FORNECEDOR & $\begin{array}{l}\text { NÃO SE } \\
\text { APLICA }\end{array}$ & $\begin{array}{c}\text { NÃO } \\
\text { POSSUI }\end{array}$ \\
\hline $\begin{array}{l}\text { Dificultar a ocorrência da } \\
\text { inflamação generalizada. }\end{array}$ & $\begin{array}{l}\text { Relatório de ensaios realizados } \\
\text { conforme a ABNT NBR } 5628 .\end{array}$ & $x$ & & & \\
\hline $\begin{array}{l}\text { Dificultar a propagação de } \\
\text { incêndio. }\end{array}$ & $\begin{array}{l}\text { Relatório de ensaios realizados } \\
\text { conforme a ABNT NBR } 5628 \text {. }\end{array}$ & $x$ & & & \\
\hline $\begin{array}{c}\text { Dificultar a propagação de incêndio } \\
\text { e preservar a estabilidade } \\
\text { estrutural da edificação }\end{array}$ & $\begin{array}{l}\text { Relatório de ensaios realizados } \\
\text { conforme a ABNT NBR } 5628 .\end{array}$ & $x$ & & & \\
\hline
\end{tabular}

Fonte: Autores (2021).

\subsection{Estanqueidade à água}

O Quadro 4 resume a análise documental referentes aos requisitos de Estanqueidade. Apesar da FAD apresentar bons resultados quanto ao atendimento dos critérios, a estanqueidade à água dos ambientes também é influenciada pela qualidade dos blocos e da argamassa empregada no assentamento e no revestimento, como retrata Kazmierczak (1989). De acordo com a FAD, a partir do ensaio de estanqueidade na parede de alvenaria com bloco cerâmico revestida com gesso na face interna, pode-se inferir que esses materiais também atendem aos critérios mínimos da NBR 15575-4 (ABNT,2013) referentes à estanqueidade à água.

Vale ressaltar que nesses documentos comprobatórios são apresentados resultados de ensaios dos ensaios dos materiais utilizados, assim como do sistema construtivo adotado, nesse caso a alvenaria de blocos cerâmicos.

Quadro 4 - Análise Documental Quanto à Estanqueidade à Água nos SVVE.

\begin{tabular}{|c|c|c|c|c|c|}
\hline REQUISITOS A ANALISAR & $\begin{array}{l}\text { DOCUMENTO } \\
\text { COMPROBATÓRIO }\end{array}$ & FAD & FORNECEDOR & $\begin{array}{l}\text { NÃO SE } \\
\text { APLICA }\end{array}$ & NÃO POSSUI \\
\hline $\begin{array}{l}\text { Infiltração de água nos } \\
\text { sistemas de vedações } \\
\text { verticais externas }\end{array}$ & $\begin{array}{l}\text { Relatório de inspeção em } \\
\text { campo, relatório de ensaio de } \\
\text { estanqueidade e projeto }\end{array}$ & $x$ & & & \\
\hline $\begin{array}{c}\text { Umidade nos SVVIE } \\
\text { decorrente da ocupação } \\
\text { do imóvel }\end{array}$ & Relatório de teste em protótipo & $x$ & & & \\
\hline
\end{tabular}

Fonte: Autores (2021).

\subsubsection{Infiltração de água nos sistemas de vedações verticais externas}

A FAD seguida pela construtora prevê um potencial atendimento ao requisito de infiltração de água nos sistemas de vedações verticais externas (requisito 10.1), desde que a alvenaria seja projetada com juntas entre os blocos preenchidas e revestidas de argamassa na face externa de no mínimo $20 \mathrm{~mm}$, bem como pintura com tinta acrílica.

Como registrado na Figura 5, não há um controle quanto à aplicação de argamassa entre as juntas dos blocos. No ponto 1 foi realizada a aplicação de argamassa nas juntas verticais entre os blocos; já no ponto 2 da mesma parede isso não foi executado. Apesar da etapa de pintura não ter 
sido acompanhada, observou-se que a tinta armazenada para execução desse serviço era a tinta acrílica, a qual é recomendada para pinturas externas.

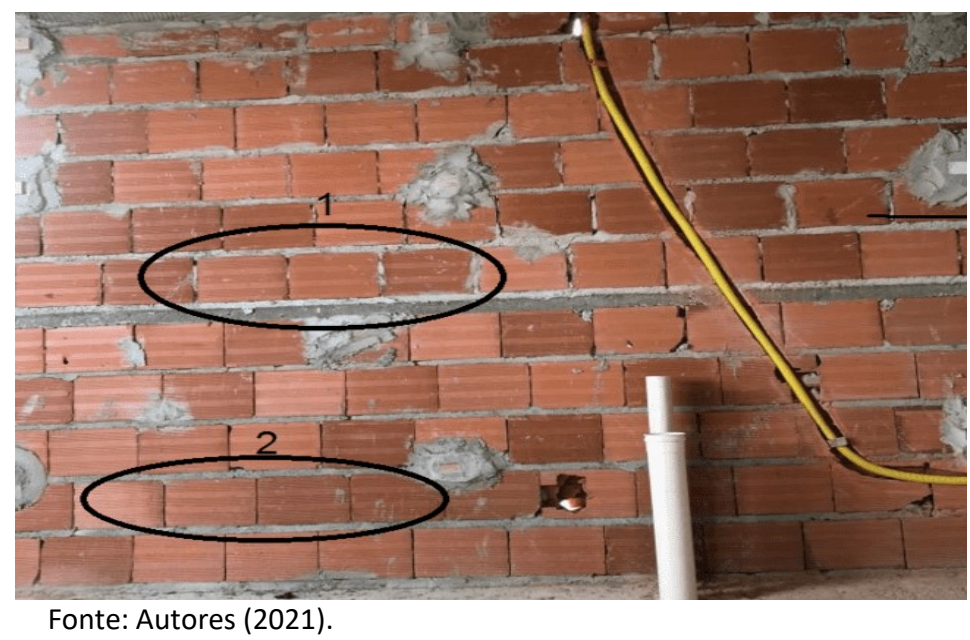

Figura 5 - Aplicação de Argamassa nas Juntas.

\subsubsection{Umidade nos SVVIE decorrente da ocupação do imóvel}

O critério de aceitação do requisito umidade nos SVVIE decorrente da ocupação do imóvel é de que a quantidade de água que penetre em uma vedação de área molhada, em um período de 24 horas, seja menor ou igual a $3 \mathrm{~cm}^{3}$.

Não foi possível observar em campo o atendimento a esse requisito, uma vez que o ensaio para comprovar o atendimento ao requisito é realizado após a finalização da obra; não sendo possível o seu acompanhamento. Contudo, a FAD para este serviço prevê um atendimento a esse requisito.

\subsection{Desempenho Térmico}

O desempenho térmico de edificações é um fator importante em habitações. Uma edificação projetada para o clima onde está inserida torna-se confortável termicamente e proporciona economia de energia. A avaliação do desempenho térmico de uma edificação engloba a resposta do projeto arquitetônico proposto em relação às trocas térmicas entre o ambiente construído e o ambiente externo (SIQUEIRA et al., 2005).

O Quadro 5 apresenta documentos comprobatórios utilizados pela empresa sobre o desempenho térmico do SVVIE. Nele é possível verificar os requisitos previstos na norma para seu desempenho térmico e os documentos que foram analisados para verificar a adequabilidade à norma.

Quadro 5 - Análise Documental Quanto ao Desempenho Térmico nos SVVE.

\begin{tabular}{|c|c|c|c|c|c|}
\hline REQUISITOS A ANALISAR & DOCUMENTO COMPROBATÓRIO & FAD & FORNECEDOR & $\begin{array}{l}\text { NÃO SE } \\
\text { APLICA }\end{array}$ & $\begin{array}{c}\text { NÃO } \\
\text { POSSUI }\end{array}$ \\
\hline $\begin{array}{c}\text { Adequação das paredes } \\
\text { externas }\end{array}$ & $\begin{array}{l}\text { Relatório que garanta cálculos } \\
\text { conforme NBR } 15220-2\end{array}$ & $X$ & & & \\
\hline
\end{tabular}

Fonte: Autores (2021).

Os materiais e elementos construtivos se comportam termicamente em função de suas propriedades. A norma NBR 15220-2 (2005) fornece tabelas com as principais propriedades 
térmicas dos materiais que compõe os elementos construtivos e apresenta os métodos de cálculo. Nesse contexto, a empresa apresentou o relatório com os cálculos realizados para atendimento ao desempenho térmico.

\subsubsection{Desempenho térmico - adequação das alvenarias externas}

O primeiro requisito a ser analisado deste tópico é o de adequação das paredes externas quanto às trocas térmicas entre o ambiente construído e o ambiente externo, que ocorre por meio da transmitância térmica $(U)$ e capacidade térmica do sistema construtivo (CT).

Os valores da transmitância térmica $(U)$ são dados em função de duas variáveis, a zona bioclimática e a absortância à radiação solar da superfície externa da fachada ( $\alpha$ ), (NBR 15575) (ABNT, 2013).

Para definir o valor de $U$, é necessário compreender o zoneamento bioclimático do território nacional. Este zoneamento foi criado para uma melhor padronização do clima brasileiro, em relação à análise térmica de ambientes. Ele divide o território brasileiro em oito zonas relativamente homogêneas quanto aos tipos de clima existentes. A cidade onde a edificação está sendo construída (Colatina-ES) situa-se na zona bioclimática 8 (ABNT, 2013; SIQUEIRA et al., 2005).

Além de conhecer a zona bioclimática, também é preciso definir a absortância à radiação solar da superfície externa da fachada $(\alpha)$. A absortância (poder de absorção), pode ser conceituada como a fração da radiação que é absorvida pela superfície quando sobre ela incide uma fonte de calor. Ela pode ser maior ou menor que 0,6. Para uma absortância maior que 0,6, há maior absorção de calor, sendo necessária uma transmitância térmica menor ou igual à $2,5 \mathrm{~W} / \mathrm{m}^{2} \cdot \mathrm{k}$.

A FAD utilizada pela empresa construtora apresenta como resultado de ensaio para este sistema de vedação, transmitância térmica de $U=2,04 \mathrm{~W} /\left(\mathrm{m}^{2} . K\right)$, ou seja, o sistema construtivo atende aos limites exigidos por norma, caso seja executado corretamente.

Quanto à capacidade térmica (CT), a norma NBR 15575-4 (ABNT, 2013) estabelece os valores mínimos e para a zona 8 não há exigências de CT. Destaca-se que esses resultados constem no documento comprobatório apresentado pela empresa (ver Quadro 5). Além disso todos esses cálculos foram refeitos pelos autores, para conferência. Além da zona bioclimática e a absortância à radiação solar da superfície externa da fachada, o tipo de material pode influenciar na transmitância térmica. O que pode ter sido comprometido pela modificação do revestimento interno da alvenaria, uso de revestimento em gesso no lugar de revestimento com argamassa.

\subsubsection{Desempenho Térmico - Aberturas para Ventilação}

O segundo item a ser avaliado referente ao desempenho térmico é a abertura para ventilação (requisito 11.3 da NBR 15575). Este requisito aplica-se somente aos ambientes de longa permanência de pessoas: salas, cozinhas e dormitórios (NBR 15575, 2013).

Os ambientes de permanência prolongada de pessoas devem possuir aberturas para ventilação com áreas que atendam à legislação específica do local da obra, incluindo Códigos de Obras, Códigos Sanitários e outros. Contudo, quando a legislação local não prevê aberturas mínimas para ventilação, adota-se para a região sudeste, na qual a área de abertura para ventilação (A) deve ser, no mínimo, $8 \%$ da área de piso. As dimensões das aberturas nos ambientes nas unidades habitacionais da obra são apresentadas no Quadro 6. Verificou-se que somente a sala de estar/jantar e a cozinha atendem à abertura mínima de ventilação. 
Quadro 6 - Resultados de Abertura de Ventilação.

\begin{tabular}{|c|c|c|c|c|}
\hline AMBIENTE & ÁREA DE PISO $\left(\mathrm{M}^{2}\right)$ & $\begin{array}{l}\text { ÁREA DE ABERTURA } \\
\left(\mathbf{M}^{2}\right)\end{array}$ & $A(\%)$ & $\begin{array}{c}\text { ATENDIMENTO A NBR } \\
15575 \text { (parte 4) }\end{array}$ \\
\hline Suíte 01 & 17,95 & 1,14 & 6,35 & Não \\
\hline Suíte 02 & 14,65 & 1,02 & 6,96 & Não \\
\hline Suíte 03 & 12,22 & 0,84 & 6,87 & Não \\
\hline Suíte 04 & 11,85 & 0,84 & 7,09 & Não \\
\hline $\begin{array}{l}\text { Sala de } \\
\text { estar/jantar }\end{array}$ & 41,24 & 4,14 & 10,04 & Sim \\
\hline Cozinha & 14,56 & 2,00 & 13,74 & Sim \\
\hline
\end{tabular}

Fonte: Autores (2021).

\subsection{Durabilidade e manutenibilidade}

Este item da "Norma de Desempenho" apresenta três requisitos, sendo eles: paredes externas - que consiste na definição dos deslocamentos, fissuras e falhas sob ação do diferencial térmico (aquecimento e resfriamento que ocorrem na edificação); VUP dos SVVIE - definindo-se que os sistemas de vedações devem ter vida útil maior ou igual à definida pela NBR 15575 (ABNT, 2013), mantendo suas características funcionais e estéticas; e manutenibilidade dos SVVIE, devendo manter a capacidade funcional do sistema durante a vida útil de projeto (NBR 15575, 2013).

Quanto aos requisitos dispostos pela Norma de Desempenho:

- Não foram observados visualmente deslocamentos, fissuras e falhas nas paredes externas sob ação do calor e do resfriamento que ocorrem na edificação. Lembrando que essas observações ocorreram durante as visitas realizadas a obra, porém, para atendimento do requisito é necessária a realização de inspeções no sistema construtivo, ao longo da vida útil de projeto;

- Não foram observados nos documentos analisados, informações da vida útil dos SVVIE;

- Quanto a manutenibilidade, a seguir serão apresentadas as constatações obtidas nas visitas técnicas e análise de documentos.

\subsubsection{Manutenibilidade e vida útil de projeto dos SVVIE}

Para atender a este requisito, as paredes externas da edificação habitacional devem apresentar Vida Útil de Projeto (VUP) igual ou superior a 40 anos, como estabelece o anexo $\mathrm{C}$ da NBR 15575 - parte 1 (ABNT, 2013a). Os SVVIE também devem ser submetidos a manutenções preventivas (sistemáticas) e, sempre que necessário, deve-se executar manutenções corretivas e de conservação previstas no manual de operação, uso e manutenção (ABNT, 2013).

Verificou-se que a empresa não possui e disponibiliza o manual de operação, uso e manutenção da edificação, visto que esta obra ainda não foi concluída. Porém, o engenheiro da empresa informou que o manual de todas as suas edificações segue um padrão, por este motivo 
considera-se válida a análise do manual de outro edifício, tornando possível desta forma, entender o comportamento da empresa quanto ao atendimento a este requisito.

O manual disponibilizado pela empresa faz uma breve e didática explicação do SVVE utilizado na edificação, apenas da vedação externa. Tal explicação é acompanhada de uma ilustração do sistema, Figura 6.

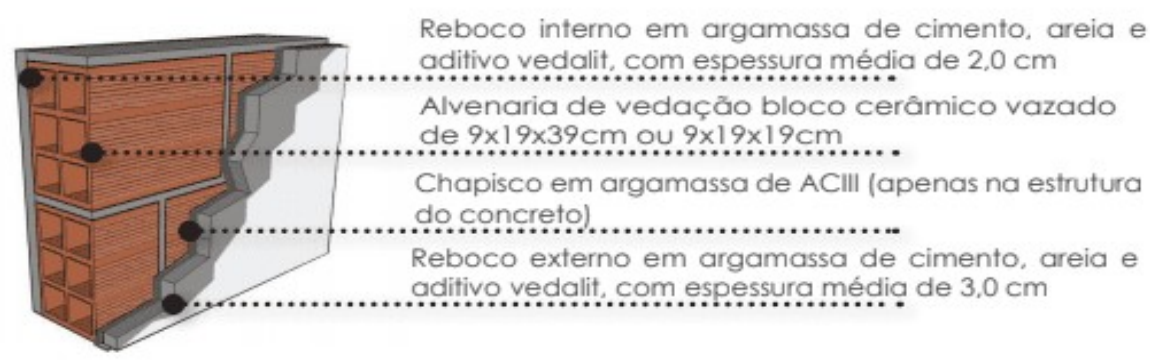

Fonte: Manual do usuário fornecido pela empresa (2021).

Figura 6 - Ilustração da Vedação Externa.

Em seguida, o manual informa ao usuário os prazos de garantias de vedação externa e da vedação interna, como apresenta a Figura 7.

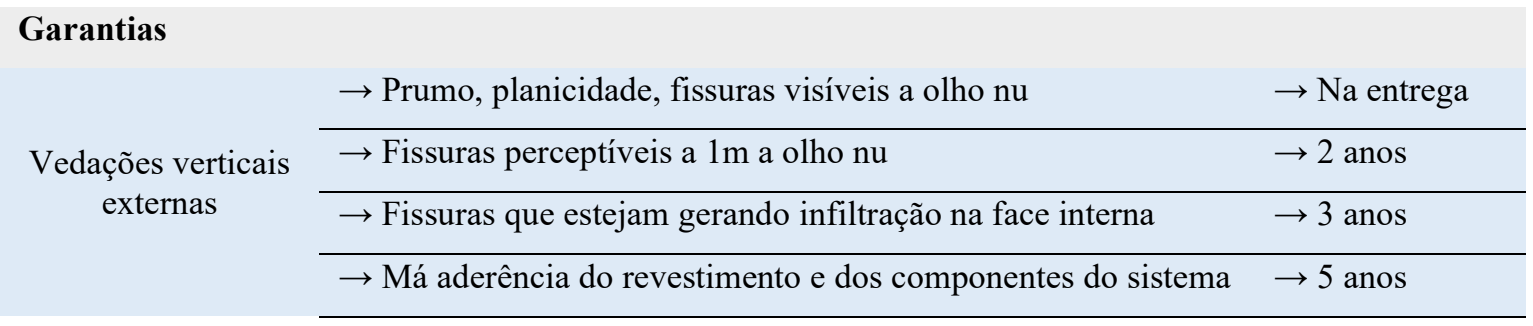

\begin{tabular}{lll} 
Garantias & $\rightarrow$ Prumo, planicidade, fissuras visíveis a olho nu & $\rightarrow$ Na entrega \\
\cline { 2 - 2 } $\begin{array}{c}\text { Vedações verticais } \\
\text { internas }\end{array}$ & $\rightarrow$ Fissuras perceptíveis a 1m a olho nu & $\rightarrow 2$ anos \\
\cline { 2 - 3 } & $\rightarrow$ segurança e integridade & $\rightarrow 5$ anos
\end{tabular}

Fonte: Manual do usuário fornecido pela empresa (2021).

Figura 7 - Informes de Garantia ao Usuário Quanto ao SVVIE.

O manual do usuário também orienta as condições de uso, porém, apenas da vedação externa. Dentre tais orientações o manual destaca duas, que são: não fazer alterações e não realizar furação e fixação de ganchos nas paredes (Figura 8).

\footnotetext{
a) Atenção!

Não demolir paredes e nem alterar a posição original prevista em projeto, tampouco fazer intervenções rasgos ou alteração nas instalações prediais.

A não observância do exposto em paredes mesmo que não estruturais causará alteração das propriedades térmicas e acústicas da mesma e a perda da garantia.
}

\section{b) Atenção! \\ Não fazer furação nos dispositivos de fixação de portas e janelas, em paredes de prumadas de água, esgoto e drenagens de água pluvial e no alinhamento vertical dos pontos elétricos. \\ Não fixar ganchos para redes sem antes verificar em projetos se existe previsão e localização para a mesma. Fonte: Manual do usuário fornecido pela empresa (2021).}

Figura 8 - Orientações de Uso Quanto ao SVVE: a) Alteração nas Paredes; b) Furação e Fixação de Ganchos nas Paredes. 
Por fim, o manual orienta quanto às manutenções preventivas informando o que deve ser realizado, quando e quem deve realizá-las, bem como a prioridade da vistoria.

O Quadro 7 apresenta as orientações sobre as manutenções sistemáticas.

Quadro 7 - Instruções para Inspeção da SVVIE.

\begin{tabular}{|c|c|c|c|}
\hline O que fazer & Quando & Quem & Prioridade \\
\hline $\begin{array}{l}\text { 4.3.1.1 Inspecionar a integridade da alvenaria interna, certificando-se da } \\
\text { não proliferação de fungos, inexistência de furos e aberturas de vãos não } \\
\text { previstos no projeto original, impactos na alvenaria e existência de } \\
\text { armários, prateleiras ou outros elementos fixados que possa representar } \\
\text { sobrecarga. } \\
\text { Manutenção corretiva: retirar a sobrecarga imediatamente e avaliar a } \\
\text { consequência da mesma. Caso verifique existência de trincas ou outro } \\
\text { dano, contratar uma empresa especializada para providências. }\end{array}$ & 1 ano & $\begin{array}{c}\text { Equipe de } \\
\text { manutenção } \\
\text { local }\end{array}$ & Alta \\
\hline $\begin{array}{l}\text { 4.3.1.2 Inspecionar a integridade da alvenaria externa (fachada), } \\
\text { verificando se há proliferação de fungos, a existência de furos e aberturas } \\
\text { de vãos não previstos no projeto original, impactos na alvenaria, a } \\
\text { existência de fissuras e as condições de aderência dos componentes } \\
\text { Manutenção corretiva - Caso verifique existência de fissuras ou algum } \\
\text { outro dano, contratar uma empresa especializada para providências. }\end{array}$ & 2 anos & $\begin{array}{c}\text { Empresa } \\
\text { capacitada }\end{array}$ & Alta \\
\hline
\end{tabular}

Fonte: Manual do usuário fornecido pela empresa (2021).

Cabe ressaltar que apesar da empresa disponibilizar um manual orientativo bem ilustrado e como uma linguagem de fácil entendimento, ele não apresenta informação da vida útil dos SVVIE, com relação a: a) ação de calor e choque térmico; b) capacidade funcional e características estéticas, compatíveis com o envelhecimento dos materiais ao longo da vida útil de projeto.

Por outro lado, a FAD faz uma observação quanto à VUP da vedação externa mencionando o possível atendimento ao requisito, desde que as paredes sejam projetadas para o estado limite último de serviço e que sejam respeitadas as condições de estanqueidade de água indicadas na respectiva ficha.

\subsection{Incumbências dos intervenientes}

Incumbências dos Intervenientes, item 4 da NBR 15575 (ABNT, 2013), trata das responsabilidades dos construtores, fornecedores, projetistas e incorporadores. A respeito dos fornecedores, verificou-se que a empresa exige destes, antes mesmo de realizada a compra de materiais, certificados e relatórios de ensaios que atestem a conformidade de seus produtos. A partir desses dados, a empresa também exige que os projetistas tenham acesso a essas informações e também tenham a responsabilidade de realizar as verificações. Além disso a empresa verifica se seus fornecedores estão no Programa Setorial da Qualidade - PSQ, que é um protocolo de regulamentação e certificação criado para avaliar e atestar a cadeia produtiva de diversos segmentos do mercado. O PSQ é uma iniciativa de entidades de classe que tem como objetivo normatizar, avaliar, analisar e certificar processos e materiais como no caso do PBQP-H (MCID, 2019).

Diante da incumbência dos intervenientes, verificou-se que são realizados estudos técnicos pelo incorporador com o objetivo de avaliar riscos previsíveis à época de projeto, como: presença de aterro sanitário, contaminação do lençol freático, dentre outros. O incorporador ou mesmo a construtora ficam responsáveis por elaborar e fornecer ao usuário o manual de uso, operação e manutenção de acordo com a norma NBR 14037 (ABNT, 2011), que trata de diretrizes para este 
documento. Esta norma estabelece os requisitos mínimos para elaboração e apresentação do conteúdo que deve constar no manual entregue pela construtora ao usuário, e deve obrigatoriamente: informar aos proprietários e ao condomínio as características técnicas da edificação; descrever procedimentos recomendáveis e obrigatórios para a conservação, uso e manutenção da edificação, bem como para a operação dos equipamentos; informar e orientar os proprietários e o condomínio, de forma didática, com relação às suas obrigações no que se refere à realização de atividades de manutenção e conservação, e de condições de utilização da edificação; recomendar ações para prevenir a ocorrência de falhas ou acidentes decorrentes de uso inadequado; e recomendar ações para contribuir para que a edificação atinja a vida útil de projeto (esta por sua vez estabelecida pelo projetista de acordo com a norma de cada sistema construtivo) (CBIC,2014).

\section{CONCLUSÃO}

A partir dos dados avaliados no presente trabalho, foi possível identificar os métodos utilizados pela empresa construtora para atendimento aos requisitos da norma ABNT NBR 15575 (ABNT, 2013), parte 4, assim como levantar quais requisitos da norma estão sendo ou não atendidos pela empresa construtora.

A avaliação de desempenho do sistema de vedação externo é comprovada pela empresa por meio da Ficha de Avaliação de Desempenho FAD SVVE 001 quanto à segurança estrutural, segurança contra incêndio, estanqueidade à água e desempenho térmico, mas o sistema de vedação que a empresa executa na obra diverge em alguns pontos do que é estabelecido, pois divergem em relação ao material utilizado e o método de execução. As dimensões do bloco cerâmico usado para revestimento interno, a direção de assentamento dos blocos, a ausência de argamassa nas juntas e uso de revestimento em gesso no lugar de argamassa são pontos divergentes entre o que é executado é o que está prescrito na FAD.

Para o requisito de segurança contra incêndio não se observou inconsistência entre a Ficha de Avaliação de Desempenho (FAD) e o executado em campo. Quanto à durabilidade e manutenibilidade, a empresa tem boas práticas para o seu atendimento, porém atende somente parcialmente ao que é específico pela norma.

Para atender aos requisitos da gestão da qualidade e garantir o bom desempenho da obra, a empresa precisa utilizar os materiais especificados na FAD, assim como atender as orientações de execução previstas nela. Essas recomendações valem tanto para a empresa construtora, quanto para os fornecedores de materiais e serviços.

Dessa forma, o sistema construtivo que a FAD preconiza para um bom desempenho não é equivalente ao sistema executado na obra, assim a empresa não cumpre com o desempenho anunciado. A empresa não comprova de forma satisfatória o desempenho estrutural, estanqueidade e o desempenho térmico da real vedação externa que executa.

A abertura para ventilação, um dos requisitos de desempenho térmico, que é avaliado por meio do projeto arquitetônico, atende apenas parcialmente a área de abertura mínima prevista na norma.

Com diversos critérios estabelecidos pela norma era inviável financeiramente para empresa realizar ensaios, pareceres técnicos, simulações e afins para avaliar o desempenho dos sistemas construtivos adotados. De forma perspicaz, a empresa elucidou essa questão com o uso das FAD's e quando não havia esse instrumento para algum dos sistemas a empresa exigia os 
relatórios de ensaios dos seus fornecedores. Ambas as posturas entendidas como corretas pelo PBQP-H e pela NBR 15575 (ABNT, 2013). Além disso, a empresa verifica se seus fornecedores estão no PSQ (Programa Setorial da Qualidade).

\section{REFERÊNCIAS}

ASSOCIAÇÃO BRASILEIRA DE NORMAS TÉCNICAS. NBR 5628: Componentes construtivos estruturais - Determinação da resistência ao fogo. Rio de Janeiro, 2001.

ASSOCIAÇÃO BRASILEIRA DE NORMAS TÉCNICAS. NBR 15220-2: Desempenho térmico de edificações. Parte 2: Método de cálculo da transmitância térmica, da capacidade térmica, do atraso térmico e do fator solar de elementos e componentes de edificações. Rio de Janeiro, 2005.

ASSOCIAÇÃO BRASILEIRA DE NORMAS TÉCNICAS. NBR 14037: Diretrizes para elaboração de manuais de uso, operação e manutenção das edificações - Requisitos para elaboração e apresentação dos conteúdos. Rio de Janeiro, 2011.

ASSOCIAÇÃO BRASILEIRA DE NORMAS TÉCNICAS. NBR 15575: Edificações Habitacionais Desempenho. Rio de Janeiro, 2013.

ASSOCIAÇÃO BRASILEIRA DE NORMAS TÉCNICAS. NBR 15575: Edificações habitacionais Desempenho Parte 1: Requisitos gerais. Rio de Janeiro, 2013a.

ASSOCIAÇÃO BRASILEIRA DE NORMAS TÉCNICAS. NBR 11675: Divisórias leves internas moduladas - Verificação da resistência aos impactos. Rio de Janeiro, 2016.

ASSOCIAÇÃO BRASILEIRA DE NORMAS TÉCNICAS. NBR 10821-3: Esquadrias para edificações. Parte 3: Esquadrias externas e internas - Métodos de ensaio. Rio de Janeiro, 2017.

ASSOCIAÇÃO BRASILEIRA DE NORMAS TÉCNICAS. NBR 15930-2: Portas de madeira para edificações. Parte 2: Requisitos. Rio de Janeiro, 2018.

ASSOCIAÇÃO BRASILEIRA DE NORMAS TÉCNICAS. NBR 14718: Esquadrias - Guarda-corpos para edificação - Requisitos, procedimentos e métodos de ensaio. Rio de Janeiro, 2019.

BORGES, C. A. M. A importância da NBR 15575 para melhoria da qualidade das habitações brasileiras. Disponível em: <https://www.aecweb.com.br/cont/a/a-importancia-da-nbr-15575para-melhoria-da-qualidade-das-habitacoesbrasileiras_7296>. Acesso em: 20 de maio. 2019.

CBIC (Fortaleza). Desempenho de edificações habitacionais: guia orientativo para atendimento à norma ABNT NBR 15575/2013. Câmara Brasileira da Indústria da Construção-Fortaleza: Gadioli Cipolla Comunicação, 2013.

CBIC (Fortaleza). Guia nacional para a elaboração do manual de uso, operação e manutenção das edificações. 2014. Disponível em: <https://cbic.org.br/wpcontent/uploads/2017/11/Guia_de_Elaboracao_de_Manuais_2014.pdf>. Acesso em: 25 out. 2019. 
CBIC (Fortaleza). Dúvidas sobre a Norma de Desempenho: especialistas respondem às principais dúvidas e elencam requisitos de suportes para elaboração de projetos. Câmara Brasileira da Indústria da Construção - CBIC, 2015. Disponível em: http://www.sindusconse.com.br/sinduscon/arquivos/CBIC.pdf

Cleto, F. R.; Oliveira, L. A.; Mitidieri Filho, C. V. O que são FADs e quais os impactos na construção civil?. 2021. Disponível em: https://www.aecweb.com.br/revista/materias/o-que-sao-fads-equais-os-impactos-na-construcao-civil/20780.

CORBIOLI, N. A norma está pegando: Visando um produto imobiliário de melhor qualidade, construtoras estão descobrindo os caminhos para superar dúvidas e dificuldades para o atendimento da NBR 15.575:2013, a primeira norma a estabelecer parâmetros mínimos de desempenho e durabilidade para edificações habitacionais do País. Revista Téchne, São Paulo, v.235, out. 2016.

CORDOVIL, L. A. B. L. Estudo da ABNT NBR 15575 - “Edificações habitacionais - Desempenho" e possíveis impactos no setor da construção civil na cidade do Rio de Janeiro. Universidade Federal do Rio de Janeiro. Rio de Janeiro, 2013.

COSTELLA, M. F.; CARUBIM, K.; PAGLIARI, C. S.; DE SOUZA, N. S., Avaliação da aplicação da norma de desempenho: estudo de caso em cinco empreendimentos. Revista de Engenharia Civil IMED. Santa Catarina, v.4, n.2, 2017.

FERREIRA, F. C. Estudo de caracterização do gesso para revestimento produzido no polo gesseiro do Araripe. Dissertação (Mestrado em Engenharia Civil) Universidade Federal de Pernambuco. Recife, 2017.

INNTELECTUS (São Paulo). Plano de Controle Tecnológico no PQO. 2018. Disponível em: <http://blog.inntelectus.com.br/plano-de-controle-tecnologico-no-pqo/>. Acesso em: 25 out. 2019.

ISO - International Organization for Standardization. ISO 10140-5: Acoustics - Laboratory measurement of sound insulation of building elements - Part 5: Requirements for test facilities and equipment. ISO/TC 43 Acoustics. 2010.

JANUZZI, U.A.; VERCESI C. Sistema de Gestão da Qualidade na Construção Civil: um estudo a partir da experiência do PBQP-H junto às empresas construtoras da cidade de Londrina. Revista Gestão Industrial, Paraná, v. 6, n. 3, p.142-143, abr. 2019.

KAZMIERCZAK, C. S. Desempenho de paredes de materiais cerâmicos a penetração de água da chuva: uma análise de fatores condicionantes. Dissertação (Mestrado em engenharia) - Programa de pós-graduação em engenharia civil/ Universidade Federal do Rio Grande do Sul. Porto Alegre, 1989.

KERN, A. P.; SILVA, A.; KAZMIERCZAK, C. S. O processo de implantação de normas de desempenho na construção: um comparativo entre a Espanha (CTE) e 57 Brasil (NBR 15575/2013). Gestão e Tecnologia de Projetos, São Paulo, v.9, n.1, p.1-13, jan/jun. 2014. 
LIMA, T. Novo Regimento do SiAC/PBQP-H: Saiba o que mudou. SIENGE PLATFORM, 2018. Disponível em: <https://www.sienge.com.br/blog/novo-regimento-do-siac/>. Acesso em: 25 de abr. 2019.

MEDEIROS, J. S. O desempenho das vedações frente à ação da água. In: Seminário Tecnologia e Gestão na Produção de Edifícios: Vedações Verticais (1‥: 1998:São Paulo) Anais; ed. Por F. H. Sabbatini, M. M. S. B. de Barros, J.S. Medeiros. São Paulo, EPUSP/PCC, 1998.

MCID - MINISTÉRIO DAS CIDADES. PBQP-H. Sistema de Avaliação da Conformidade de Empresas de Serviços e Obras da Construção Civil - SiAC. Disponível em: <http://pbqph.cidades.gov.br/pbqp_apresentacao.php/>. Acesso em:15 de abr. 2019.

PERES, L.; BENACHOUR, M.; SANTOS, V. A. Gesso: produção e utilização na construção civil. Recife: SEBRAE. 2008. 120 p.

QUINALIA, E. Revestimento de Gesso liso: desempenado ou sarrafeado. Revista Téchne, São Paulo, ano 13, n. 99, p. 36-38, jun. 2005.

SACHS, A.; NAKAMURA, J. Desempenho revisado. Revista Téchne, n. 192, p. 42-49, março 2013.

SHIN, H. B. Norma de desempenho NBR 15575: estudo das práticas adotadas por construtoras e dos impactos ocorridos no mercado da construção civil. Universidade Federal do Rio de Janeiro. Rio de Janeiro. 2016.

SILVA, M. M. de A. Diretrizes para o projeto de alvenaria de vedação. Monografia (graduação em engenharia) Escola Politécnica da Universidade de São Paulo. São Paulo, 2003.

SINAENCO. Os impactos da Norma de Desempenho no Setor da Arquitetura e Engenharia Consultiva. Sindicato da Arquitetura e da Engenharia. São Paulo. 2015.

SIQUEIRA, T. C. P. A.; AKUTSU, M.; LOPES, J. I. E.; SOUZA, H. A. Dados climáticos para avaliação de desempenho térmico de edificações. Rem: Revista Escola de Minas, [s.I.], v. 58, n. 2, p.133-138, jun. 2005.

ZANINI, F. Proposta de um modelo de implementação de PBQP-H em construtoras de pequeno porte: um estudo de caso em uma construtora de Curitiba. 2011. 105 f. Trabalho de Conclusão de Curso - Curso de Engenharia de Produção Civil. Universidade Tecnológica Federal do Paraná, Curitiba, 2011. Disponível em: <http://repositorio.roca.utfpr.edu.br/jspui/handle/1/372>. Acesso em: 25 set. 2019. 